\title{
Academician L. A. Artsimovich
}

Lev Andreevitch Artsimovitch was a member of the Steering Committee of the European Physical Society and after the Society's foundation served as a member of the Executive Committee until his death. His interest in the affairs of the Society was personal, cordial and intense. His observations in discussions were sharp, unconventional, spiced with humour and always to the point. In circles of

Academician L. A. Artsimovitch was a brilliant scientist who combined profound theoretical insight with thorough knowledge of experimental techniques; he was an outstanding organizer of science, teacher and public figure. He began his first studies of $\mathrm{X}$-ray physics over 40 years ago and came to the overall leadership of the Soviet research programme in the field of high-temperature plasma and controllable thermonuclear synthesis. $\mathrm{His}$ career, which he began as a laboratory assistant in the PhysicoTechnical Institute of the Academy of Sciences of the USSR, culminated in leadership of a major department and membership in the Presidium of the Academy of Sciences.

Lev Andreevitch Artsimovitch was born in Moscow on 25 February, 1909. $\mathrm{He}$ graduated from the Byelorussia State University in Minsk in 1928. In April 1930, he began to work in the Leningrad Physico-Technical Institute where he held posts of laboratory assistant, engineer, junior research fellow, director of laboratory and director of department.

In 1930-1932, L. Artsimovitch performed his first studies in the Leningrad Physico-Technical Institute which were devoted to X-ray physics. Together with A. I. Alikhanov, he conducted a comprehensive experimental study of total internal reflection of $X$-rays from thin metal layers. In 193435, L. Artsimovitch studied properties of slow neutrons. Together with I. V. Kurchatov, he rigorously proved by experiment for the first time that slow neutron absorption in hydrogenous materials is due to neutron capture by protons.

In 1936, when, after the experiments of Shepland and other workers, there was some questioning of the applicability of the laws of conservation of energy and momentum to the elementary interactions of electrons with positrons, L. A. Artsimovitch proposed to check the validity of these laws for the process of positron annihilation.
EPS, Lev Andreevitch was respected not only as a profound physicist with broad interests, but equally as a man of integrity, culture, and compassion. In his quiet, inconspicuous, but persistent, manner he contributed essentially to the goals of EPS. The results of many of his efforts became known only indirectly and often incidentally, because he did not seek publicity. His views on Society and on the role

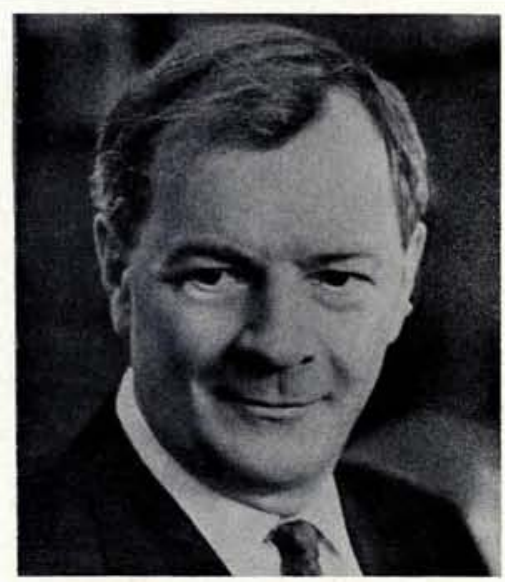

The experiments conducted by him, together with Alikhanov and Alikhanyan, gave the complete proof of the validity of the conservation laws for this phenomena. Beginning from 1936, L. A. Artsimovitch conducted a wide range of experiments in the field of physics of fast electrons. The works of L. A. Artsimovitch were the first experimental study of the laws of bremsstrahlung for monoenergetic electron beams with energies of 0.5 to $3 \mathrm{MeV}$. These studies made it possible to compare the predictions of quantum mechanics with the experimental results and to demonstrate the validity of quantum mechanics in relation to the interaction of fast electrons with matter.

The experimental works of L. A. Artsimovitch were distinguished by exacting analysis and self-criticism, so that his experimental results were always highly reliable.

In 1942-1944, L. A. Artsimovitch was engaged in development of electronoptical devices. He suggested the basic theorem defining the resolution of electron-optical systems and developed designs for some electron-optical amplifiers.

In 1943 he suggested, developing the idea of the betatron, a new method for resonance acceleration of electrons by a high-frequency field in a circular magnetic system. Later, when physics can play in improving the lot of mankind were optimistic. His opinion on the thermonuclear fusion problem, for example, was that a solution will be found whenever such a solution will be demanded. With the death of L.A. Artsimovitch, the European Physical Society has lost a very dear triend.

EPS Secretary 1968-73 L. Jansen

V. I. Veksler formulated his famous principle of phase stability, this method was rendered practicable. In 1945 , L. A. Artsimovitch, in collaboration with I. Ya. Pomeranchuk, developed the fundamentals of the classical theory for magnetic bremsstrahlung of fast electrons in circular accelerators.

Beginning in 1951, L. A. Artsimovitch devoted his scientific activities to experimental development of the foundations of high-temperature plasma physics in connexion with the problem of controllable thermonuclear synthesis. The solution of this problem will provide mankind with a source of energy which is practically inexhaustible. In 1951-1954, L. A. Artsimovitch and his collaborators conducted a series of studies of powerful impulsive discharges of short duration. These experiments revealed some important features of behaviour of a hot plasma column in the magnetic field of the current flowing through it. It was found, in particular, that such plasma can produce very fast particles. These studies for the first time demonstrated the great importance of the stability of plasma configurations. L. A. Artsimovitch prepared a report about these studies which made a great impression in Harwell, where it was delivered by I. V. Kurchatov during the visit of the Soviet State delegation to Great Britain in 1956.

For more than 15 years, L. A. Artsimovitch concentrated his activities on the systems for hot plasma generation, known as 'Tokamak'. Using these systems, he and his collaborators for the first time produced stable plasma with the lifetime up to 15 20 milliseconds and the density approaching $10^{14}$, while the ion temperature was above 8 million degrees (the electron temperature was 30 million degrees). Using 'Tokamak', L. A. Artsimovitch and his collaborators for the first time produced a physical thermonuclear reaction in a stable quasi-stationary plasma. L. A. Artsi- 
movitch suggested the main ideas for the further development of the 'Tokamak' systems : new methods of heating and ways of changing the magnetic configuration.

In 1930 , L. A. Artsimovitch began his teaching activities, first in the Leningrad University, later in the Moscow Physico-Engineering Institute and, from 1953, in the Lomonosov State University in Moscow. He was a brilliant lecturer who could clearly and vividly present the most complicated aspects of modern physics, and he enjoyed a well-deserved esteem and popularity among the students.

From 1944, L. A. Artsimovitch worked in the Kurchatov Atomic Energy Institute. In 1946 he was elected a corresponding member of the Academy of Sciences of the USSR, in 1953 he was elected a full member of the Academy. Since 1957, he permanently held the post of Secretary of the Department of Physics and Astronomy in the Academy of Sciences and was a Member of the Academy Presidium.

L. A. Artsimovitch was held in a high respect by Soviet and foreign scientists which was due not only to his outstanding scientific works but also to his personal qualities - his personal integrity, his profound and versatile learning, his literary and oratory brilliance, his fine sense of humour. When he delivered a scientific report, the report was always vivid and fascinating. When he presided over a conference, the conference was not protracted and invariably produced results. When he wrote a scientific monograph or a popular article, it was always exciting reading.

For his outstanding contribution to the development of science and technology, L. A. Artsimovitch was awarded the title of a Hero of Socialist Labour; he was awarded Lenin and
State Prizes and was decorated with three Orders of Lenin and two Orders of the Red Banner of Labour.

L. A. Artsimovitch was elected an honorary member of national academies of many countries.

L. A. Artsimovitch was a member of the Lenin Prize Science and Technology Committee, a member of the Commission on the Scientific Problems of Disarmament affiliated to the Presidium of the Academy of Sciences of the USSR, Chairman of the National Committee of Soviet Physicists, a member of the Executive Committee and Council of the European Physical Society, a member of the Permanent Committee of the Pugwash Conference; he took part in many important Soviet and international conferences.

National Committee of Soviet Physicists

\section{Spring Meeting of Council}

\section{2-23 March 1973, Sinaia, Romania}

Although there had been a state of emergency declared in Romania because of a sudden fall of $60 \mathrm{~cm}$ of snow, all the delegates to the Spring Meeting of Council in the ski resort of Sinaia arrived safely. The warm hospitality and friendly reception by the Romanian hosts more than compensated for any inconveniences that the weather imposed.

As President H. B. G. Casimir stated in his reply to the welcome by I. Ursu :

'We must thank our Romanian colleagues for putting up with a state of emergency, just so that we can enjoy the sight of fresh snow in the beautiful mountains !' Representatives from 20 different European countries had gathered for the Council meeting which was once more to prove that, despite the success of the Society's promotion of the advance of physics in Europe and neighbouring countries, there are essential weaknesses in financial support which require urgent attention.

\section{President's report}

President H. B. G. Casimir began by indicating that, after its Second EPS General Conference in Wiesbaden in October 1972, the European Physical Society should begin to look forward to the Third General Conference in 1975. He then asked the Chairmen of Advisory Committees to report.

\section{Applied Physics and Physics in Industry}

L. A. A. Thomas had formally taken over Chairmanship only on 21 March 1973 and he called upon Council to express appreciation of the activities of his predecessor, O. G. Folberth. The Committee had now completed its work to attract Associate Members (see Europhysics News, April 1973, page 5). The new Chairman saw that the two immediate tasks of the Committee were: to ensure adequate coverage of applied physics and physics in industry at Europhysics Conferences; and to organize meetings to examine how 'environmental physics' could contribute basic analyses and physical solutions to environmental problems.

\section{Conferences}

P. Radvanyi briefly described the current activities of sponsorship and approval of Europhysics Conferences, for which he invited early applications in future. He explained the need for a committee on education to scrutinize proposals for summerschools. Also, he declared the Committee's intention to survey Europhysics Conferences. Finally, a plea was put in for better representation on the Committee from the various regions of the Society.

\section{Physics and Society}

This Committee, under the Chairmanship of G. Diemer, had decided that, following two years of analysis which culminated in discussion of a working paper at the Second General Conference, action was now required. Six recommendations were to be submitted for the approval of the next meeting of the Executive Committee.

\section{Publications}

J. Depireux reported that after the work on the general physics journals in Europe, the Committee were now moving ahead with examination of specialized journals for the 'Europhysics Journal' label.

\section{Closing Remarks}

The President then recommended to Council that an Advisory Committee on Education should be set up by the Executive Committee, and this met with widespread approval. Before closing his report, the President announced the generous offer by E. H. S. Burhop to set up a fund so that, at each. EPS General Conference, there could be a lecture on the theme of physics and society. This would be known as the Cecil Powell Lecture, in honour of the work and the efforts of this eminent scientist to further co-operation amongst physicists froin all European countries.

\section{Divisions}

Representatives of Divisions outlined current activities and plans for 1973 , much as describc in Europhysics News, February 1973, pages 1-3. It was agreed that a pilot study and budget analysis should be carried out on the proposal to launch a Europhysics Conference Abstracts. 